\title{
Retinol-binding protein-4 was associated with sensitization to inhalant allergens in the elderly population
}

\author{
Byung-Keun Kim ${ }^{1,}$, Woo-Jung Song ${ }^{2,}$, Bomi Seo ${ }^{3,4,5}$, Ju-Young Kim6, Sae-Hoon Kim,4,5, Hak C. Jang ${ }^{3}$, \\ Ki-Woong Kim ${ }^{7}$, and Yoon-Seok Chang $3,4,5$
}

\begin{abstract}
${ }^{1}$ Department of Internal Medicine, Korea University College of Medicine, Seoul; ${ }^{2}$ Department of Internal Medicine, Asan Medical Center, University of Ulsan College of Medicine, Seoul; ${ }^{3}$ Department of Internal Medicine, Seoul National University Bundang Hospital, Seongnam; ${ }^{4}$ Department of Internal Medicine, Seoul National University College of Medicine, Seoul; ${ }^{5}$ Institute of Allergy and Clinical Immunology, Seoul National University Medical Research Center, Seoul; ${ }^{6}$ Department of Internal Medicine, Gyeongsang National University Changwon Hospital, Changwon; ${ }^{7}$ Department of Neuropsychiatry, Seoul National University College of Medicine, Seoul, Korea
\end{abstract}

Received: October 23, 2019

Revised : January 28, 2020

Accepted: March 18, 2020
Background/Aims: Recent evidence suggests an association between allergic sensitization and metabolic markers. However, this association has rarely been examined in the elderly. Retinol-binding protein-4 (RBP-4) is a recently identified adipokine that acts on the muscle and liver affecting insulin sensitivity. We evaluated the association between metabolic parameters and allergic sensitization in the elderly.

Methods: We analysed the database of the Korean Longitudinal Study on Health and Aging cohort study conducted during 2005 to 2006. Atopy was identified by inhalant allergen skin prick test. Metabolic conditions were assessed using anthropometric indices and serum biomarkers such as fasting glucose, lipid, adiponectin, and RBP-4.

Results: Among the 854 elderly subjects, $17.2 \%$ had atopy. Plasma RBP-4 levels were significantly higher in the atopic elderly than nonatopic elderly $(p=0.003)$. When RBP-4 percentiles were categorized as under three groups, the prevalence of atopy and current rhinitis increased significantly with percentiles of RBP-4 levels ( $p=0.019$ and $p=0.007$, respectively). Log RBP-4 was associated with atopy (odds ratio $[\mathrm{OR}], 4.10 ; p=0.009)$ and current rhinitis $(\mathrm{OR}, 2.73 ; p=0.014)$, but not with current asthma (OR, 1.17; $p=0.824)$. Higher RBP-4 level in atopic elderly was also observed in current rhinitis patients. Atopy, but not current rhinitis, showed significant relationships with log RBP-4 levels in multivariate analyses adjusted for other metabolic markers including body mass index.

Conclusions: RBP-4 positively associated with atopy in the general elderly population irrespective of other metabolic markers.

Keywords: Atopy; Elderly; Retinol-binding protein-4

\section{Correspondence to Yoon-Seok Chang, M.D.}

Department of Internal Medicine, Seoul National University Bundang Hospital, 82 Gumiro 173beon-gil, Bundang-gu, Seongnam 13620, Korea

Tel: +82-31-787-7023, Fax: +82-31-787-4052, E-mail: addchang@snu.ac.kr https://orcid.org/0000-0003-3157-0447

*These authors contributed equally to this work. 


\section{INTRODUCTION}

For several decades, prevalence of allergic conditions has been increasing with industrialization and urbanization. Moreover, the increase in the prevalence of metabolic disorders including obesity and diabetes mellitus has been witnessed. Thus, the association between allergic conditions and metabolic disorders has been one of the major topics of academic interest $[1,2]$. Asthma is one of the well-known allergic conditions that is closely associated with metabolic disorders, particularly with obesity even in the elderly $[3,4]$. Several factors have been suggested to explain their association including the following: direct mechanical effects on the airways or adipokine-mediated systemic inflammation $[4,5]$. However, studies about their association are lacking, and controversial findings about the metabolic association between rhinitis and atopy are observed $[1,6,7]$.

Adiponectin is the most abundant secretory protein derived from adipocyte. It has insulin-sensitizing, anti-inflammatory and anti-atherogenic functions. Serum adiponectin concentration is inversely associated with metabolic diseases such as type 2 diabetes mellitus, the metabolic syndrome, and coronary heart disease [8]. There are a few studies that adiponectin correlates inversely with asthma [9]. Retinol-binding protein-4 (RBP4) is a recently identified adipokine that acts on the muscle and/or liver affecting insulin sensitivity [10,11]. RBP-4 is reported to be related with obesity and its comorbidities such as insulin resistance, type 2 diabetes, and metabolic syndrome [10]. Plasma RBP-4 levels are also increased with body mass index (BMI) [11]. The decrease in plasma RBP-4 level predicts the improvement in insulin sensitivity more specifically than other adipokines [10]. The association between RBP-4 and asthma has reported [12] but there are few subsequent studies.

In the European Global Allergy and Asthma European Network (GA2LEN) survey, among the several obesity indices such as BMI, waist circumference, and serum adiponectin and leptin levels, none were significantly associated with nasal allergies or atopy in adults [13]. On the contrary, in the 2005 to 2006 National Health and Nutrition Examination Survey in the United States, obesity was associated with nonallergic rhinitis in adults but not in children [6]. These conflicting results suggest the possibility that the associations are subject to popu- lation characteristics. To our knowledge, the association between metabolic parameters of metabolic disorders and atopy has not been properly examined in the elderly general population. Here, we aimed to explore the association between metabolic parameters and atopy, in the elderly ( $\geq 65$ years) using a comprehensive database of a community-population cohort study.

\section{METHODS}

\section{Study population}

Cross-sectional data were obtained from the baseline survey of the Korean Longitudinal Study on Health and Aging (KLoSHA) conducted from September 2005 to September 2006. The KLoSHA is a population-based cohort study that was developed to obtain comprehensive information of common geriatric disorders and to establish a comprehensive database of general health and functional status in Korean elderly [14]. Random sampling among total population of Seongnam city aged 65 years or older and all of these subjects were invited by research coordinators [14]. Interviews on medical history and social details were conducted by trained nurses who were certified to conduct epidemiologic study and assessment of geriatric patients. All the assessments were performed at Seoul National University Bundang Hospital. All subjects were fully informed on the study protocol and were provided with written statements of informed consent signed by themselves or their legal guardians. The Institutional Review Board of Seoul National University Bundang Hospital approved this study (IRB No: B-1211/178-112).

\section{Definition of atopy, current asthma, and allergic current rhinitis}

Skin prick test was performed for the following 12 aeroallergens common in Korea, as previously described [15]: Dermatophagoides pteronyssinus, D. farinae, cat epithelia, dog epithelia, Blattella germanica, Aspergillus fumigatus, Alternaria tenuis, tree pollen mixture 1 (alder, hazel, popular, elm, and willow), tree pollen mixture 2 (birch, beech, oak, and plane tree), grass pollen mixture (velvet grass, orchard grass, rye grass, timothy grass, Kentucky blue grass, and meadow grass), mugwort, and ragweed (Allergopharma, Reinbek, Germany). A positive control 
( $1 \mathrm{mg} / \mathrm{mL}$ of histamine; Allergopharma) and a negative control (0.9\% sodium chloride, $4 \mathrm{mg} / \mathrm{mL}$ of phenol, and $563 \mathrm{mg} / \mathrm{mL}$ of glycerol; Allergopharma) were included in all tests. Skin prick test was performed on the volar aspects of the forearms by introducing the tip of a 26-gauge needle through a drop of test solution at a $90^{\circ}$ angle against the skin. The longest and perpendicular diameters of each wheal were measured using Vernier calipers at 15 minutes after the prick, and the arithmetic mean of the recorded measurements was used as the representative value. The positivity of allergen skin response was determined using the cutoff level of allergen/histamine wheal size ratio $\geq 1$. Atopy was defined to be positive if a subject exhibited positive skin response to any one or more of the 12 tested allergens. Allergic respiratory diseases were assessed by affirmatively answering the following questions, as previous described $[7,16]$. For current asthma, (1) have you ever had been diagnosed with asthma? (ever asthma) and (2) have you had a wheezing or whistling in the chest during the last 12 months? (current wheeze) [7]. For current rhinitis, have you had sneezing and a runny or blocked nose without a cold during the last 12 months? [16].

\section{Anthropometric measures and laboratory evalua- tions}

Height and body weight were measured to the nearest $0.1 \mathrm{~cm}$ or $0.1 \mathrm{~kg}$ in subjects wearing light clothing while barefoot. Waist circumference (WC) was measured at the narrowest point between the lower limit of the rib cage and the iliac crest. Fasting plasma glucose (FPG) levels were measured after a 12-hour fasting and were determined using the glucose oxidase method. Subjects were categorized into the following three groups: normal, < $110 \mathrm{mg} / \mathrm{dL}$; impaired fasting glucose, 110 to $125 \mathrm{mg} / \mathrm{dL}$; and diabetes, $\geq 126 \mathrm{mg} / \mathrm{dL}$. Total cholesterol, triglyceride (TG), and high-density lipoprotein cholesterol (HDL-C) were measured enzymatically using an autoanalyzer (Hitachi 747, Hitachi, Tokyo, Japan). C-reactive protein (CRP) values were measured by turbidimetric immunoassay using the VITROS 5.1 FS Chemistry System (Ortho Clinical Diagnostics, Raritan, NJ, USA). In case of subjects whose CRP values were below the detection level of the assay (0.01 mg/dL), CRP values were arbitrarily assigned as half of the lower limit (0.005 mg/dL). Plasma RBP-4 levels were measured using an enzyme-linked immunosorbent assay (ELISA, AdipoGen Inc., College of Life Science and Biotechnology, Korea University, Seoul, Korea). Adiponectin levels were measured using an ELISA kit according to the manufacturer's instructions (AdipoGen).

\section{Statistical analyses}

Descriptive values of continuous variables are expressed in mean \pm standard deviation if normally distributed. Variables such as TG, HDL-C, CRP, adiponectin, and RBP-4 concentrations were logarithmically transformed before statistical analysis to approximate normal distribution. However, the mean values of the variables were presented as untransformed form in descriptive tables. Differences between the atopic and nonatopic groups were tested using independent $t$ test, or chi-square test. Spearman's bivariate correlation test was performed to evaluate correlations among variables. Multivariate logistic regression test was performed to investigate the association after adjusting for several variables showing statistically significant association with RBP-4. All statistical analyses were performed using IBM SPSS version 22.o (IBM Corp., Armonk, NY, USA).

\section{RESULTS}

\section{Plasma RBP-4 levels were significantly higher in the atopic elderly than in the nonatopic elderly}

Baseline characteristics of the study subjects were described previously [15]. A total of 854 subjects with available skin prick test results were included in the present analysis. Of note, the presence of atopy had significant association with high serum RBP-4 levels (Table 1), whereas it was not associated with BMI, WC, FPG, and cholesterol levels. Plasma RBP-4 levels were significantly higher in the atopic elderly than in the nonatopic elderly $(63.3 \pm 26.4 \mu \mathrm{g} / \mathrm{mL}$ vs. $57.0 \pm 24.8 \mu \mathrm{g} / \mathrm{mL}, p=0.003)$, whereas plasma adiponectin levels were marginally lower in the atopic subjects $(9.7 \pm 6.3 \mu \mathrm{g} / \mathrm{mL}$ vs. $8.9 \pm 6.7 \mu \mathrm{g} /$ $\mathrm{mL}, p=0.05$ ) (Table 1 ) than in the nonatopic subjects. Hypertension and diabetes were related to RBP-4 level ( $p$ $=0.027$ and $p=0.015$, respectively) and other medical histories (dyslipidemia, thyroid disease, hepatitis including liver cirrhosis, gastrointestinal disease, malignancy, and heart diseases except cardiovascular disease) were not 
Table 1. Baseline characteristics of subjects according to atopic status

\begin{tabular}{|c|c|c|c|}
\hline Variable & Atopy (-) & Atopy $(+)$ & $p$ value \\
\hline Total & $707(82.8)$ & $147(17.2)$ & \\
\hline Age, yr & $75.82 \pm 8.71$ & $74.27 \pm 8.04$ & $0.036^{\mathrm{a}}$ \\
\hline Male sex, \% & 41.16 & 53.06 & $0.008^{a}$ \\
\hline Body mass index, $\mathrm{kg} / \mathrm{m}^{2}$ & $24.06 \pm 3.27$ & $24.21 \pm 3.24$ & 0.610 \\
\hline Waist circumference, $\mathrm{cm}$ & $86.57 \pm 9.57$ & $86.94 \pm 7.92$ & 0.628 \\
\hline Smoking & & & 0.136 \\
\hline Nonsmoker & $444(63.0)$ & $81(55 \cdot 5)$ & \\
\hline Ex-smoker & $176(25.0)$ & $48(32.9)$ & \\
\hline Current smoker & $85(12.1)$ & $17(11.6)$ & \\
\hline Fasting plasma glucose, $\mathrm{mg} / \mathrm{dL}$ & $109.17 \pm 26.08$ & $111.16 \pm 25.98$ & 0.401 \\
\hline Total cholesterol, mg/dL & $204.06 \pm 38.44$ & $204 \cdot 31 \pm 34.58$ & 0.942 \\
\hline Triglyceride, $\mathrm{mg} / \mathrm{dL}^{\mathrm{b}}$ & $132.82 \pm 76.88$ & $141.8 \pm 83.24$ & 0.097 \\
\hline High-density lipoprotein cholesterol, mg/dL & $60.81 \pm 15 \cdot 52$ & $60.56 \pm 15.4$ & 0.841 \\
\hline Low-density lipoprotein cholesterol, mg/dL & $116.89 \pm 34.21$ & $115.38 \pm 32.33$ & 0.623 \\
\hline C-reactive protein, $\mathrm{mg} / \mathrm{dL}^{\mathrm{b}}$ & $0.24 \pm 0.7$ & $0.26 \pm 0.57$ & 0.256 \\
\hline Adiponectin, $\mu \mathrm{g} / \mathrm{mL}^{\mathrm{b}}$ & $9.7 \pm 6.25$ & $8.88 \pm 6.73$ & $0.040^{\mathrm{a}}$ \\
\hline Retinol-binding protein-4, $\mu \mathrm{g} / \mathrm{mL}^{\mathrm{b}}$ & $56.99 \pm 24.79$ & $63.25 \pm 26.36$ & $0.003^{\mathrm{a}}$ \\
\hline Current asthma & $46(6.53)$ & $15(10.2)$ & 0.117 \\
\hline Current rhinitis & $185(26.28)$ & $43(29.25)$ & 0.459 \\
\hline
\end{tabular}

Values are presented as number (\%) or mean $\pm \mathrm{SD}$.

a $p<0.05$.

${ }^{\mathrm{b}}$ Logarithmically transformed before statistical analysis to approximate normal distribution. Untransformed data are presented in the table.

related to RBP-4 level. As the association between RBP-4 levels and allergic conditions was not reported in any general population samples before, we decided to focus on the association with RBP-4 levels here.

\section{Atopy and current rhinitis increased significantly with percentiles of RBP-4 levels}

Plasma RBP-4 levels showed positive associations with BMI and FPG (Fig. 1). Among the continuous variables, plasma RBP-4 level was statistically significantly correlated with BMI, WC, total cholesterol, and TG levels and inversely correlated with age and CRP level (Table 2). When RBP-4 percentiles were categorized as under $15 \%(<34.57 \mu \mathrm{g} / \mathrm{mL}), 15 \%$ to $85 \%$ (34.57 to $81.39 \mu \mathrm{g} / \mathrm{mL}$ ), and over $85 \%(>81.39 \mu \mathrm{g} / \mathrm{mL})$, the prevalence of atopy and current rhinitis increased significantly with percentiles of RBP- 4 levels ( $p=0.019$ and $p=0.007$, respectively), but current asthma did not ( $p=0.507$ ) (Fig. 2). However, cur- rent rhinitis and atopy did not show any significant associations with any indices of metabolic syndrome, such as glucose intolerance, BMI, and dyslipidemia (data not described). With subgroup analysis, RBP-4 levels were higher in the atopic elderly in current rhinitis and current asthma patients, but statistical significance was shown only in current rhinitis patients $(63.3 \pm 18.9 \mu \mathrm{g} /$ $\mathrm{mL}$ vs. $51.8 \pm 20.6 \mu \mathrm{g} / \mathrm{mL}, p=0.042 ; 56.6 \pm 19.7 \mu \mathrm{g} / \mathrm{mL}$ vs. $54.1 \pm 24.5 \mu \mathrm{g} / \mathrm{mL}, p=0.560$, respectively).

\section{RBP-4 was positively associated with atopy even after multivariate analysis}

To determine if plasma RBP-4 levels were independently associated with atopy or allergic symptoms, multivariate logistic regression tests were performed with potential confounding factors showing statistically significant association with RBP-4 (Table 3). When adjusted for age, sex, smoking status, hypertension, and diabetes, 

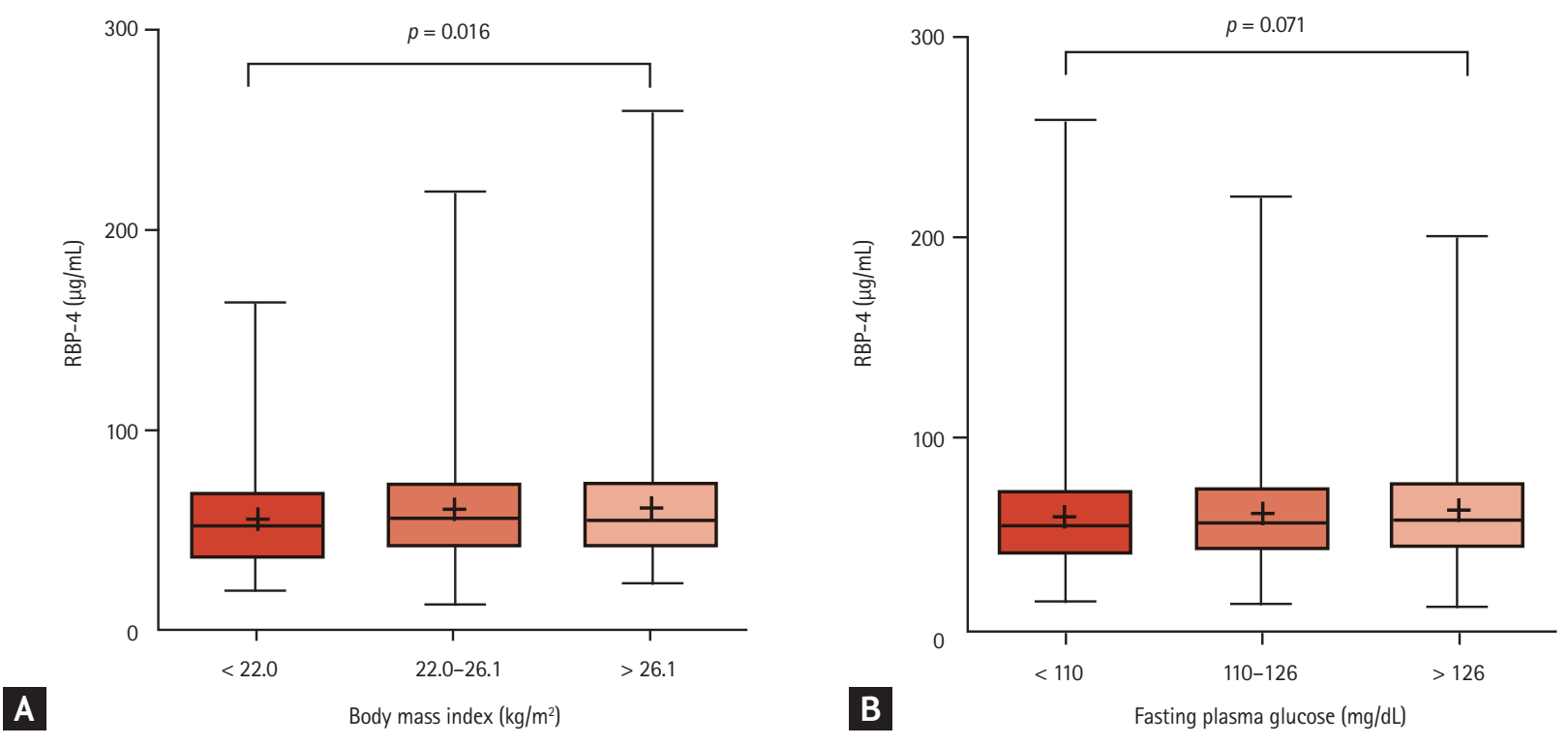

Figure 1. Box-Whisker plot of retinol-binding protein-4 (RBP-4) level according to body mass index (BMI) quartile (A) and diabetes status categorized by fasting plasma glucose (FPG) (B). (A) Plasma RBP-4 levels showed positive associations with BMI (lowest tertile of BMI, <22.0 kg/m $\mathrm{m}^{2}$; mid-tertile, 22.0 to $26.1 \mathrm{~kg} / \mathrm{m}^{2}$; and highest tertile, $\geq 26.1 \mathrm{~kg} / \mathrm{m}^{2} ; p=0.016$ ). (B) Geometric mean values of RBP-4 for each BMI tertile-based group were as follows: 55.19, 60.67, and 61.29 $\mu \mathrm{g} / \mathrm{mL}$, respectively. RBP-4 levels were higher in diabetes and impaired fasting glucose (IFG) group than normal FPG group (57.5, 60.1, and 61.5 mg/dL, respectively) but the difference was not statistically significant $(p=0.071)$.

Table 2. Correlations between retinol-binding protein-4 and variables

\begin{tabular}{lcc}
\hline Variable & $r$ & p value \\
\hline Age, yr & -0.082 & $0.009^{\mathrm{a}}$ \\
Body mass index, $\mathrm{kg} / \mathrm{m}^{2}$ & 0.086 & $0.011^{\mathrm{a}}$ \\
Waist circumference, $\mathrm{cm}$ & 0.067 & $0.049^{\mathrm{a}}$ \\
Fasting plasma glucose, $\mathrm{mg} / \mathrm{dL}$ & 0.040 & 0.204 \\
Total cholesterol, mg/dL & 0.099 & $0.002^{\mathrm{a}}$ \\
Triglyceride, $\mathrm{mg} / \mathrm{dL}$ & 0.181 & $<0.001^{\mathrm{b}}$ \\
High-density lipoprotein & -0.020 & 0.527 \\
cholesterol, mg/dL & & \\
C-reactive $\mathrm{protein}, \mathrm{mg} / \mathrm{dL}$ & -0.123 & $<0.001^{\mathrm{b}}$ \\
Adiponectin, $\mu \mathrm{g} / \mathrm{mL}$ & 0.033 & 0.204 \\
\hline
\end{tabular}

${ }^{a} p<0.05$.

${ }^{\mathrm{b}} \mathrm{p}<0.01$.

$\log \mathrm{RBP}-4$ was associated with atopy (odds ratio [OR], 4.62; 95\% confidence interval [95\% CI], 1.24 to $17.24 ; p=$ 0.023) and current rhinitis (OR, 2.80; 95\% CI, 1.07 to 7.34; $p=0.036)$, but not with current asthma (OR, 0.30; $95 \%$ CI, 0.06 to 1.53; $p=0.148)$. Log RBP-4 remained significantly associated with atopy after additionally adjusting

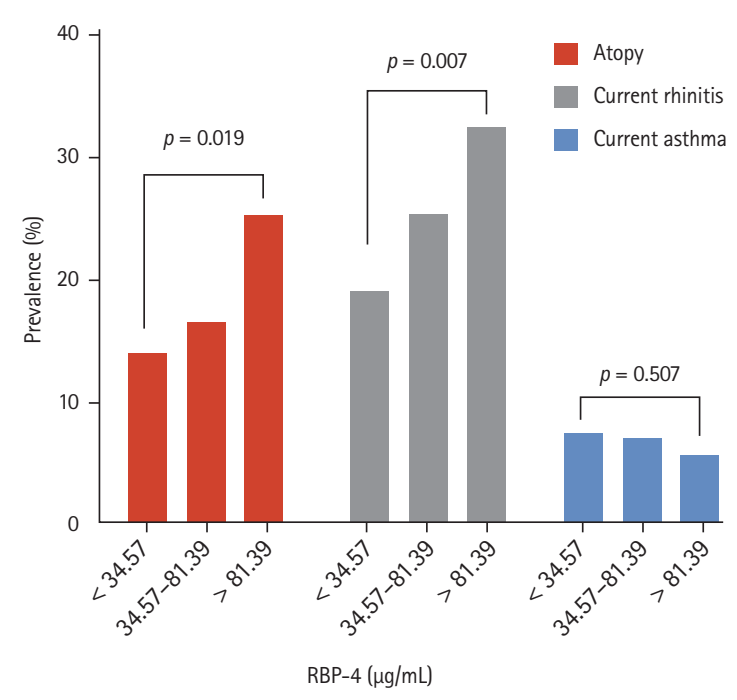

Figure 2. Prevalence of atopy, current rhinitis, and current asthma according to retinol-binding protein-4 (RBP-4) levels. RBP-4 levels were stratified as under $15 \%(<34.57 \mu \mathrm{g} / \mathrm{mL}), 15 \%$ to $85 \%$ (34.57 to $81.39 \mu \mathrm{g} / \mathrm{mL})$, and over $85 \%$ (> 81.39 $\mu \mathrm{g} / \mathrm{mL})$.

the confounding factors including BMI, $\log$ TG, and log CRP (OR, 5.28; 95\% CI, 1.28 to $21.85 ; p=0.022$ ). However, the association with current rhinitis did not remain significant after adjusting for these variables (Table 3). 
Table 3. The association of RBP-4 or adiponectin with atopy, current rhinitis, and current asthma

\begin{tabular}{|c|c|c|c|}
\hline \multirow{2}{*}{ Variable } & \multicolumn{3}{|c|}{ Adjusted OR (95\% CI) } \\
\hline & Atopy & Current rhinitis & Current asthma \\
\hline $\log \mathrm{RBP}-4^{\mathrm{a}}$ & $4.62(1.24-17.24)^{b}$ & $2.80(1.07-7.34)^{b}$ & $0.30(0.06-1.53)$ \\
\hline + BMI & $5.59(1.41-22.14)^{b}$ & $2.35(0.84-6.52)$ & $0.24(0.04-1.36)$ \\
\hline$+\log T G$ & $3.85(1.01-14.76)^{b}$ & $2.65(0.99-7.06)$ & $0.31(0.06-1.61)$ \\
\hline$+\log \mathrm{CRP}$ & $5.03(1.33-19.03)^{b}$ & $2.71(1.02-7.19)^{b}$ & $0.43(0.08-2.28)$ \\
\hline + All of the above & $5.28(1.28-21.85)^{b}$ & $2.12(0.74-6.11)$ & $0.37(0.06-2.28)$ \\
\hline $\log _{\text {adiponectin }}{ }^{\mathrm{a}}$ & $0.52(0.26-1.03)$ & $1.44(0.83-2.49)$ & $1.55(0.60-4.02)$ \\
\hline + BMI & $0.57(0.27-1.21)$ & $1.50(0.83-2.68)$ & $1.75(0.63-4.90)$ \\
\hline$+\log T G$ & $0.57(0.28-1.18)$ & $1.63(0.92-2.88)$ & $1.50(0.57-3.98)$ \\
\hline$+\log C R P$ & $0.51(0.25-1.03)$ & $1.46(0.84-2.53)$ & $1.64(0.62-4.33)$ \\
\hline+ All of the above & $0.63(0.29-1.34)$ & $1.60(0.88-2.92)$ & $1.62(0.57-4.65)$ \\
\hline
\end{tabular}

RBP-4, retinol-binding protein-4; OR, odds ratio; CI, confidence interval; BMI, body mass index; TG, triglyceride; CRP, C-reactive protein.

${ }^{a}$ Adjusted for age, sex, smoking status, diabetes, and hypertension.

${ }^{\mathrm{b}} \mathrm{p}<0.05$.

Log adiponectin did not show any significant association with atopy, current rhinitis, or current asthma after adjusting for age, gender, and smoking status (Table 3).

\section{DISCUSSION}

The present study identified a significant association between plasma RBP-4 levels and atopy in the elderly. Higher RBP-4 level in atopic elderly was also observed in current rhinitis patients. The significance of their association was independent of various confounding factors including metabolic parameters and medical history. Current rhinitis showed a positive association both in plasma RBP-4, but their association was not significant in multivariate analyses.

So far, there are very few reports in the literature concerning the association between RBP-4 and allergic conditions. In a case-control study of prepubertal children, high plasma RBP-4 levels correlated with lower forced expiratory volume in 1 second/forced vital capacity (FEV1/FVC) or forced expiratory flow at $25 \%$ and $75 \%$ (FEF25-75) in male asthmatics; however, no significant difference in its level was found between asthmatics and controls [12]. Zinkeviciene et al. [17] suggested RBP-4 as a possible serum biomarker in allergic contact derma- titis. However, to our knowledge, none has examined their association in general populations. In the present analyses of community-based elderly population, the prevalence of atopy and current rhinitis, but not current asthma, showed significant associations with RBP-4 levels (Fig. 2). Furthermore, the association between plasma RBP-4 levels and atopy was significant independent on the confounding factors (Table 3). These suggest a potential implication of RBP- 4 in the pathogenesis of inhalant allergen sensitization in the elderly.

Obesity may directly affect the asthma phenotype by several factors including the following: mechanical effects, genetic interactions with environmental exposure, and inflammatory cascade generated by the adipose tissue $[2,3]$. Obesity and metabolic syndrome can influence sex hormones and, therefore, possibly influence the development of atopy $[18,19]$. Additionally, many researchers have been trying to reveal the mechanism with animal model $[1,20]$. However, the reports concerning the relationship between atopy and metabolic syndrome are still conflicting. Metabolic syndrome induces systemic inflammation, and it could potentially have an effect on asthma onset and severity [4]. There are several reports concerning the epidemiologic association between metabolic syndrome and asthma [21,22]. However, its independent effect on asthma is still controversial, and it 
seems to be smaller than obesity itself [5] and moreover, evidence is further conflicting, or rather scarce for allergic conditions other than asthma. There are fewer researches concerning the effect of obesity and metabolic syndrome to atopy or rhinitis than asthma. Clinically, rhinitis symptoms might be associated with an increased risk of metabolic syndrome and obesity $[23,24]$, but some epidemiologic studies show irrelevance or negative association $[21,25]$. Previous study reported that the risk of atopy in obesity was increased 50\% in a report with 1,997 adult subjects in Canada [26]. However, there are many other reports with negative findings $[1,27,28]$.

Indeed, the obese state is characterized by the socalled chronic low-grade systemic inflammation. Obesity and metabolic syndrome might contribute to atopy in an alternative manner. Adipokines are important endocrine mediators because they modulate adipose tissue function, and they might represent molecular links of obesity and metabolic syndrome with asthma and atopy $[1,9]$. The effect of leptin, adiponectin in asthma and atopy has been previously evaluated in other articles, but it showed no association except asthma score [13]. Meanwhile, many diseases that seem to be associated with serum RBP-4 level other than metabolic disorders including diabetes and obesity were reported. RBP-4 is associated with chronic liver diseases such as cirrhosis and non-alcoholic fatty liver disease [29]. Also, RBP-4 seems to be associated with inflammatory processes and several diseases such as inflammatory bowel disease [30], psoriasis [31], cardiomyopathy [32], and cancer [33]. Nevertheless, the mechanisms of the association between RBP-4 and these diseases are still unclear. It remains similar with the other allergic conditions $[12,17]$.

We showed the association of atopy and RBP-4, adipokine which is a marker of inflammation in elderly in community-based cohort. Also, it was independent of markers of metabolic syndrome including BMI. Although there is no report on the association of atopy with RBP-4 in youth population which is mainly sensitized, previous study in children showing the association between RBP-4 and FEV1 were also independent of BMI [12]. These results suggest that the association between atopy and RBP-4 may differ in the mechanisms that explain the association between obesity and asthma. One possible hypothesis to explain the association between atopy and RBP-4 irrelevant to metabolic syn- drome, which we showed, is vitamin A. RBP-4 is a specific plasma carrier of retinol and transports vitamin A from the liver to target peripheral tissues [30]. RBP-4 levels are positively associated with vitamin A levels [34], and it plays significant roles in immunomodulation and $\mathrm{T}$ cell regulation [35]. There are several reports that reveal excessive vitamin $A$ increases the incidence of atopy $[36,37]$. Although not all studies support the same result [38], there is laboratory evidence that vitamin A increases serum immunoglobulin $\mathrm{E}(\mathrm{IgE})$ and $\mathrm{IgG}$ responses and its deficiency decreases interleukin (IL)-4 and IL-5 concentrations [39]. The association between atopy and RBP-4, even though atopy and BMI alone were not related (Table 1) as previous report [15], supports this interpretation.

In general, most sensitization occurs in children and youth. However, atopy exists in elderly, and de novo sensitization can also occur. Atopy in elderly is easy to overlook because its incidence is lower than younger people. However, there is evidence of strong correlation between atopy and clinical symptoms including rhinitis and airway hypersensitivity in elderly [40]. Therefore, atopy in elderly should also need to be interested. Our study is also meaningful as an exploratory study in that it suggests possible hypothesis of its mechanism in association. Additionally, in our study, the relationship between atopy and RBP-4 level was also consistent in current rhinitis group and this can give clinical implications. However, there are several limitations in our study. First, our definition of current rhinitis and current asthma was based on a self-reported questionnaire survey and our analyses had cross-sectional nature and, thus, could not determine the causal relationship. Second our findings on RBP-4 association had an explorative nature and we have hypothesized to explain this association, but there is a lack of experimental evidence to support it. Finally, the external validity of our conclusions is still unclear and, thus, warrants further validation in different ethnicities or age groups. Therefore, further studies are needed to show the association in other age group and explain its mechanism. Despite these limitations, our study has novelty in that this is the first report on the novel adipokine RBP-4 and allergic conditions in the elderly general population sample. Moreover, no studies in the literature have reported the association between RBP-4 levels and atopy in the gen- 
eral population.

The present study examined the metabolic association between allergic conditions in the elderly general population. RBP-4 had significant association with atopy, which was independent on the markers of metabolic syndrome including BMI and this is the first study that shows the association. Although the mechanism of effect of RBP-4 in elderly atopy warrant further investigations, the present analyses indicate a potential role of novel adipokine in the pathophysiology of atopy in the elderly and can be a clue for further study.

\section{KEY MESSAGE}

1. Retinol-binding protein-4 (RBP-4) positively associated with atopy in the general elderly population irrespective of other metabolic markers.

2. Higher RBP-4 level in atopic elderly was also observed in current rhinitis patients.

3. This is the first report on the RBP-4 and allergic conditions in the elderly general population.

\section{Conflict of interest}

No potential conflict of interest relevant to this article was reported.

\section{REFERENCES}

1. Boulet LP. Obesity and atopy. Clin Exp Allergy 2015;45:7586.

2. Serafino-Agrusa L, Spatafora M, Scichilone N. Asthma and metabolic syndrome: current knowledge and future perspectives. World J Clin Cases 2015;3:285-292.

3. Brisbon N, Plumb J, Brawer R, Paxman D. The asthma and obesity epidemics: the role played by the built environment: a public health perspective. J Allergy Clin Immunol 2005;115:1024-1028.

4. Peters U, Dixon AE, Forno E. Obesity and asthma. J Allergy Clin Immunol 2018;141:1169-1179.

5. Assad N, Qualls C, Smith LJ, et al. Body mass index is a stronger predictor than the metabolic syndrome for future asthma in women: the longitudinal CARDIA study. Am J Respir Crit Care Med 2013;188:319-326.
6. Han YY, Forno E, Gogna M, Celedon JC. Obesity and rhinitis in a nationwide study of children and adults in the United States. J Allergy Clin Immunol 2016;137:1460-1465.

7. Song WJ, Kim SH, Lim S, et al. Association between obesity and asthma in the elderly population: potential roles of abdominal subcutaneous adiposity and sarcopenia. Ann Allergy Asthma Immunol 2012;109:243-248.

8. Choi SH, Ku EJ, Hong ES, et al. High serum adiponectin concentration and low body mass index are significantly associated with increased all-cause and cardiovascular mortality in an elderly cohort, "adiponectin paradox": the Korean Longitudinal Study on Health and Aging (KLoSHA). Int J Cardiol 2015;183:91-97.

9. Ali Assad N, Sood A. Leptin, adiponectin and pulmonary diseases. Biochimie 2012;94:2180-2189.

10. Kotnik P, Fischer-Posovszky P, Wabitsch M. RBP4: a controversial adipokine. Eur J Endocrinol 2011;165:703-711.

11. Yang Q, Graham TE, Mody N, et al. Serum retinol binding protein 4 contributes to insulin resistance in obesity and type 2 diabetes. Nature 2005;436:356-362.

12. Park YH, Kim KW, Lee KE, Kim ES, Sohn MH, Kim KE. Clinical implications of serum retinol-binding protein 4 in asthmatic children. J Korean Med Sci 2009;24:10101014 .

13. Newson RB, Jones M, Forsberg B, et al. The association of asthma, nasal allergies, and positive skin prick tests with obesity, leptin, and adiponectin. Clin Exp Allergy 2014;44:250-260.

14. Park JH, Lim S, Lim J, et al. An overview of the Korean longitudinal study on health and aging. Psychiatry Investig 2007;4:84-95.

15. Song WJ, Lee SM, Kim MH, et al. Histamine and allergen skin reactivity in the elderly population: results from the Korean Longitudinal Study on Health and Aging. Ann Allergy Asthma Immunol 2011;107:344-352.

16. Song WJ, Kim MY, Jo EJ, et al. Rhinitis in a community elderly population: relationships with age, atopy, and asthma. Ann Allergy Asthma Immunol 2013;111:347-351.

17. Zinkeviciene A, Kainov D, Lastauskiene E, et al. Serum biomarkers of allergic contact dermatitis: a pilot study. Int Arch Allergy Immunol 2015;168:161-164.

18. Vieira VJ, Ronan AM, Windt MR, Tagliaferro AR. Elevated atopy in healthy obese women. Am J Clin Nutr 2005;82:504-509.

19. Siroux V, Curt F, Oryszczyn MP, Maccario J, Kauffmann F. Role of gender and hormone-related events on IgE, 
atopy, and eosinophils in the Epidemiological Study on the Genetics and Environment of Asthma, bronchial hyperresponsiveness and atopy. J Allergy Clin Immunol 2004;114:491-498.

20. Dietze J, Bocking C, Heverhagen JT, Voelker MN, Renz H. Obesity lowers the threshold of allergic sensitization and augments airway eosinophilia in a mouse model of asthma. Allergy 2012;67:1519-1529.

21. Brumpton BM, Camargo CA Jr, Romundstad PR, Langhammer A, Chen Y, Mai XM. Metabolic syndrome and incidence of asthma in adults: the HUNT study. Eur Respir J 2013;42:1495-1502.

22. Thuesen BH, Husemoen LL, Hersoug LG, Pisinger C, Linneberg A. Insulin resistance as a predictor of incident asthma-like symptoms in adults. Clin Exp Allergy 2009;39:700-707.

23. Craig TJ, McCann JL, Gurevich F, Davies MJ. The correlation between allergic rhinitis and sleep disturbance. J Allergy Clin Immunol 2004;114(5 Suppl):S139-S145.

24. Gangwisch JE. Epidemiological evidence for the links between sleep, circadian rhythms and metabolism. Obes Rev 2009;10(Suppl 2):37-45.

25. Hwang IC, Lee YJ, Ahn HY, Lee SM. Association between allergic rhinitis and metabolic conditions: a nationwide survey in Korea. Allergy Asthma Clin Immunol 2016;12:5.

26. Chen Y, Rennie D, Cormier Y, Dosman J. Association between obesity and atopy in adults. Int Arch Allergy Immunol 2010;153:372-377.

27. Leung TF, Kong AP, Chan IH, et al. Association between obesity and atopy in Chinese schoolchildren. Int Arch Allergy Immunol 2009;149:133-140.

28. Schachter LM, Peat JK, Salome CM. Asthma and atopy in overweight children. Thorax 2003;58:1031-1035.

29. Nobili V, Alkhouri N, Alisi A, et al. Retinol-binding protein 4: a promising circulating marker of liver damage in pediatric nonalcoholic fatty liver disease. Clin Gastroenterol Hepatol 2009;7:575-579.

30. Roma E, Krini M, Hantzi E, et al. Retinol binding protein
4 in children with inflammatory bowel disease: a negative correlation with the disease activity. Hippokratia 2012;16:360-365.

31. Gul FC, Cicek D, Kaman D, Demir B, Nazik H. Changes of serum lipocalin-2 and retinol binding protein-4 levels in patients with psoriasis and Behcet's disease. Eur J Dermatol 2015;25:195-197.

32. Bobbert $P$, Weithauser A, Andres J, et al. Increased plasma retinol binding protein 4 levels in patients with inflammatory cardiomyopathy. Eur J Heart Fail 2009;11:11631168.

33. Noy N, Li L, Abola MV, Berger NA. Is retinol binding protein 4 a link between adiposity and cancer? Horm Mol Biol Clin Investig 2015;23:39-46.

34. Erikstrup C, Mortensen OH, Nielsen AR, et al. RBP-to-retinol ratio, but not total RBP, is elevated in patients with type 2 diabetes. Diabetes Obes Metab 2009;11:204-212.

35. Kim CH. Retinoic acid, immunity, and inflammation. Vitam Horm 2011;86:83-101.

36. Kiraly N, Benn CS, Biering-Sorensen S, et al. Vitamin A supplementation and BCG vaccination at birth may affect atopy in childhood: long-term follow-up of a randomized controlled trial. Allergy 2013;68:1168-1176.

37. Aage S, Kiraly N, Da Costa K, et al. Neonatal vitamin A supplementation associated with increased atopy in girls. Allergy 2015;70:985-994.

38. Nurmatov U, Devereux G, Sheikh A. Nutrients and foods for the primary prevention of asthma and allergy: systematic review and meta-analysis. J Allergy Clin Immunol 2011;127:724-733.

39. Schuster GU, Kenyon NJ, Stephensen CB. Vitamin A deficiency decreases and high dietary vitamin $\mathrm{A}$ increases disease severity in the mouse model of asthma. J Immunol 2008;180:1834-1842.

40. Viswanathan RK, Mathur SK. Role of allergen sensitization in older adults. Curr Allergy Asthma Rep 2011;11:427433 . 